\title{
A Correlation Study among Achievement Motivation, Goal-Setting and L2 Learning Strategy in EFL Context
}

\author{
Jing $\operatorname{Han}^{1} \&$ Qingsheng $\mathrm{Lu}^{1}$ \\ ${ }^{1}$ Foreign Languages College, Jiangxi Normal University, China \\ Correspondence: Qingsheng Lu, Foreign Languages College, Jiangxi Normal University, Yaohu Campus, 99 \\ Ziyang road, Nanchang, Jiangxi, 330022, China. E-mail: 1972898831@qq.com
}

Received: November 16, 2017 Accepted: December 16, 2017 Online Published: December 19, 2017

doi: 10.5539/elt.v11n2p5

URL: http://doi.org/10.5539/elt.v11n2p5

\begin{abstract}
Achievement motivation as one of the most important parts in learning motivation indicates a concern with success in competition with some standard of excellence. Learners who are highly motivated to learn a language are likely to use a variety of strategies. Besides achievement motivation, goal setting, a very important cognitive mediator between motivational antecedents and motivational behaviour, becomes another variable influencing learners' strategy use. Therefore, the current study will focus the influence of achievement motivation and goal setting on learners' strategy use, aiming to deal with (1) the typical types of learning strategies held by the college students under investigation; (2) effect of different levels of achievement motivation on the use of learning strategies; (3) the relationship among goal-setting, learning strategies and achievement motivation. The results show that compensation and metacognitive strategies are reported as being used the most frequently, followed by cognitive and affective strategies, while the three least frequently used individual strategies involve "use words differently", "start L2 conversation", and "ask for native's help". Concerning the relationship between achievement motivation and strategy use, motive to achieve success (Ms) is positively and significantly correlated with four of the six types of learning strategies, i.e. cognitive, metacognitive, affective and social strategies. On the contrary, motive to avoid failure (Mf) is negatively but not significantly correlated with all the strategies. With regard to goal-setting and strategy use, the study shows that all six learning strategies are significantly correlated with goal-setting except affective strategies. As to relationship between goal-setting and achievement motivation, motive to achieve success (Ms) has significant positive relations with three levels of goal-setting, while motive to avoid failure (Mf) is positively related to "short-term goal" and "mastery goal".
\end{abstract}

Keywords: achievement motivation, goal-setting, learning strategies, relationship

\section{Introduction}

Since 21 century, foreign language teaching gradually has transferred from "teacher-centeredness" to "student-centeredness". To make students be autonomous learners, cultivating students to use learning strategies has become one of major targets of language teaching, in which students are pushed to be responsible for their own learning. As we all know, without sufficient motivation, even individuals with remarkable abilities cannot accomplish long-term goals. Thus it would be helpful to integrate both the "will" and "skill" in our study. In order to bridge the gap, this study aims to explore the relationship between the learning strategy use and two personal modifiable factors ---achievement motivation and goal-setting.

\section{Literature Review}

\subsection{Concept of Achievement Motivation}

Motivation refers to the progress whereby goal-directs behavior is instigated and sustained. Motivation drives and directs behavior. Achievement motivation governs the behavior relevant to achievement and learning. Achievement motivation, also referred to as the need for achievement, is defined now as a concern with success in competition with some standard of excellence. People who have a strong achievement aims will show high achievement motivation to do things in order to reach their goal (Tella, 2007). Singh (2011) regards that the people are motivated to constantly change themselves as one climbs the ladder of age and maturity.

The theory of achievement motivation put forward by Atkinson (1996) is one of the classic theories which attributes the strength of a tendency to undertake some activity to the cognitive expectation (or belief) that the 
activity will produce a certain consequence and attractiveness (or value) of the consequence to the individual. At the same time, Atkinson (1996) categorizes it into the positive motivation to strive for success (Ms) and the negative inhibitory tendency to avoid failure (Mf). And one person whose achievement behaviors not only relate to their achievement motivation, but also their expectation to success or failure, which is discussed as motivation to strive for success or tendency to avoid failure (Tella, 2007).

\subsection{The Goal-Setting}

In Locke and Latham's (1989) goal setting theory, a goal is seen as the 'engine' to fire the action and provide the direction in which to act. From 1990 to 2002, researchers have already done about 400 studies to show that the more difficult and higher goals are, the higher level of achievement gets. There is a linear relationship between goal difficulty and task achievement (Locke \& Latham 2006). Dornyei and Otto (2001) takes an intermediary position and regards goals as the first concrete mental representations of a desired end state; goals, in their opinion, are an indispensable step in the motivated behavioral sequence. Different types of goal orientations have been identified by researchers, which have been contrasted as mastery goal and performance goal. With a performance goal orientation, there is a concern with being judged able, and one shows evidence of ability by being successful, by outperforming others, or by achieving success with little effort. With a mastery goal, the importance of this goal is to develop new skills. The attainment of mastery is related to learners' effort made in the learning process. Goal theories propose that human action is spurred by purpose, and for action to take place, goals have to be set and pursued by choice.

\subsection{Learning Strategies}

The terms which have been used to describe strategies such as "learning behaviors" (Wesche, 1977; Politzer \& McGroarty, 1985), "cognitive processes" (Rubin, 1981), and "tactics" (Seliger, 1984) (Ellis, 1994) and to account for their purpose to acquire knowledge, to regulate learning, to make learning more effective vary, but they have much in common. Oxford defines strategies in general terms as "steps taken by learners to enhance their learning" (Oxford, 1990). Cohen (2014) explores that three factors influence the using of learning strategies : robust repertoire of learning strategies, self-identity and language skills.

In this study, learning strategies are defined as "specific actions taken by the learner to make learning easier, faster, more enjoyable, more self-directed, more effective, and more transferable to new situations"(Oxford, 1990:8).The instrument Strategy Inventory for Language learning (SILL) has gained popularity for eliciting levels of strategy use through being administered in a variety of learning environments and thus calls for comparisons of strategy use to be made in different cultures. The two classes of direct and indirect learning strategies are subdivided into a total of six groups. Direct learning strategies include memory, cognitive and compensation strategies. Indirect learning strategies consist of metacognitive, affective and social strategies.

\subsection{Studies of Achievement Motivation and Goal-setting and Learning Strategies}

\subsubsection{Studies of Achievement Motivation and Goal-setting}

The goal theory has differentiated three separate types of goals: mastery goals, performance goals and social goals in the area of achievement motivation (Ames, 1992). In the context of school learning, which involves operating in a relatively structured environment, students with mastery goals outperform students with either performance or social goals.

Thus goal-setting is a very important cognitive mediator between Motivational Antecedents and Motivational Behavior because higher goals lead to higher levels of performance. Because of the close relation of goal-setting and motivated behavior, goal-setting is also linked to final achievement, as the Chinese saying goes, "High goals usually result in medium attainment". Moeller, Theiler and Wu (2011) analyzes the relationship between goal setting and achievement from the perspectives of teacher and students by using means of linear model.

\subsubsection{Studies of Achievement Motivation and Learning Strategies}

Researchers have demonstrated that motivation for language learning plays a key role in strategy use. The study, conducted by R. Oxford and M. Nyikos (1989), provides many insights about variables influencing the choice of learning strategies by foreign language students in a conventional classroom setting. Results of this study showed that motivation was the most important factor affecting language learning strategy use. Highly motivated learners were likely to use a variety of strategies, when they learn language. The findings support Gardner's (1985) study: "attitudes and motivation are important because they determine the extent to which the individuals will actively involve themselves in learning the language. The prime determining factor is motivation".

Meece, Anderman .M and Anderman.H (2006) investigates the influence of environment in classroom and 
school on students' motivation and achievement based on the framework of achievement goal structure. Evidence from the research indicates that atmosphere of school which emphasizes high ability and competition for high scores will increase the performance of some students, while some others shows low motivation under this situation.

In China, Wen (2001) reportes a study on developmental patterns of modifiable learner variables (i.e. motivation, beliefs and strategies) and their relations based on longitudinal questionnaire data. Motivation investigated in this study referred to intrinsic and extrinsic motivation on the basis of Biggs' (1979) clarification, while learning strategies were based on the framework of Wen's own classification. The research results indicated that the relations among the variables such as motivation and learning strategies were fairly stable.

Bernaus, Gardner (2008) explores that effects of the learning strategies influence on the students' motivation and English achievement from the perspective of teacher and students. The conclusion of this research is that there is no effect of strategies on motivation from teacher's view, while there exists positive effect on achievement and motivation of students from students' view.

There has been an increasing amount of researches on the relationship between motivation and learners' strategy use in second and foreign language learning as mentioned above. Now the aspects of motivation under investigations are just the tip of the iceberg in view of wide discussions on complicated motivational components in second and foreign language learning areas. However, little has been known about the relationship between strategy use and achievement motivation, which calls for attention both in FLL context and educational settings.

\subsubsection{Studies of Goal-setting and Learning Strategies}

In the LISREL model of the internal structure of EFL Motivation (Qin \& Wen, 2002), goal-setting was found to have a direct effect on Motivational Behavior, this means that when learners set high goals in learning, they worked hard toward them.

Dweck and Legget (1988), and Lee, Locke and Latham (1989) argued that mastery goals are thought to lead to adaptive behavioral responses such as increased effort or strategy shifting, whereas performance goals give rise to maladaptive responses, and that goals influence performance by increasing intensity, persistence, and attention. Lee, Palmer and Wehmeyer (2009) provides teachers the methods of using strategies, supporting students to set goals to their learning and evaluating the goal.

\section{Methodology}

\subsection{Research Questions}

The present study attempts to find out the answer to the following questions:

(1) What typical types of learning strategies are held by the college students under investigation?

(2) Do different levels of achievement motivation have an effect on the use of learning strategies? If yes, to what degree?

(3) What is the relationship among goal-setting, learning strategies and achievement motivation?

\subsection{Subjects}

230 third year non-English majors from two major universities in Jiangxi province were asked to complete the questionnaire. 37 invalid copies of questionnaire were eliminated as those students who did not respond to the questionnaire correctly. As a result, only 193 students' data were adopted for statistical analysis, among which 83 were males and 110 were females. The subjects had studied English formally for six years in junior and senior high schools and for two more years as university students.

\subsection{Instruments}

Three questionnaires are used in this study, including Achievement Scale (AMS) of T.Gjesme \& R.Nygaard (1970), a self-made goal-setting scale and Oxford's (1990) Strategy Inventory for Language Learning (SILL). Chinese version of AMS was employed to refer specifically to an English learning context. The SILL was translated into Chinese in order to guarantee a better comprehension of the questions and more spontaneous responses. According to Oxford and Nyikos (1989) both the SILL and AMS were found to have content validity by "using classificatory agreement between two independent raters". The Chinese SILL had a Cronbach alpha of .90; the Chinese AMS had a Cronbach alpha of .78.

\subsubsection{Personal Information}

Personal information involved in the study includes gender, speciality, the types of colleges or universities. 


\subsubsection{Achievement Motivation Scale (AMS)}

The measuring instrument of motive for success and failure (AMS) which we adopted in the survey is developed by T. Gjesme and R. Nygard (1970), covers 15 items respectively, in which affective experience contents are linked with certain subjective probability of success. The scales of the two motives correlate negatively together. Each item has 4 response alternatives which are expressed as: (1) does not apply to me; (2) applies only partly to me; (3) applies predominantly (to a large extent) to me; (4) applies exactly to me.

Ms $(n=15 ; \alpha=83)$. This scale assesses the motive for approaching success, which is characterized as the capacity to anticipate pleasure or pride, such as "I like the task that I can try my best to accomplish it".

$\operatorname{Mf}(\mathrm{n}=15 ; \alpha=.87)$. This measure assesses the motive for avoiding failure, which is characterized as the capacity to anticipate pain or embarrassment, such as "I worry about the problem that I am not sure if I am able to solve it".

\subsubsection{Goal-setting Questionnaire}

This questionnaire was designed on the basis of the classification of properties of goal-setting by former researches. Each property was categorized into specific levels (items). This 20-item questionnaire is to be answered on a Likert scale of 1 to 5 to assess students' goal-setting. The points on the scale are: (1) never or almost never true of me; (2) generally not true of me; (3) somewhat true of me; (4) generally true of me; and (5) always true of me. The categories of goal-setting are presented as follows:

Goal source $(n=2)$. This measures where the student's goal-setting come from. Goal specificity $(n=2)$. This measures how clear and elaborate the student's goal specifications are. Goal difficulty $(n=5)$. This measures the general probability of attaining the student's respective goal. Goal proximity $(\mathrm{n}=2)$. This measures the time scale or range of the student's goal. Level of aspiration of goal $(n=2)$. This measures what importance the learner attaches to English learning target, in other word, whether the learner sets a mastery goal or a performance goal. Goal harmony/conflict $(n=4)$. This measures how the student deals with multiple learning goals in learning English. Goal commitment $(\mathrm{n}=2)$. This measures what judgements the learner puts in the learning target.

\subsubsection{Strategy Inventory for Language Learning (SILL)}

The SILL, developed by Rebecca Oxford (1990), has been translated into Chinese in order to guarantee a greater comprehension of the questions and more spontaneous responses. The student's frequency of learning strategies is assessed through a 50-item questionnaire, which consists of strategy descriptions to be answered on a Likert scale of 1 to 5. The points on the scale are: (1) never or almost never true of me; (2) generally not true of me; (3) somewhat true of me; (4) generally true of me; and (5) always true of me. The SILL is based on six categories of strategies, which is presented as follows:

The internal consistency reliability coefficient of the Chinese Version SILL $(n=50)$, assessed by means of Cronbach $\alpha$, presents as .90 , while the six subscales range from .54 to .82 . Considering that "Cronbach $\alpha$ is dependent upon the number of items a scale contains" (Backhouse, et al. 1982, cited from Dorney, 1990: 51), these coefficients are acceptable.

Memory strategies consist of 9 items which assess how frequently students use them to memorize and receive new knowledge.

Cognitive strategies include 14 items which determines to what extent learners use them to comprehend and generate new knowledge.

Compensation strategies cover 6 items assessing to what extent the learner utilizes the information available for either comprehension or production despite limitations in knowledge.

Metacognitive strategies consist of 9 items. They assess the frequency with which learners use them to control their own cognition.

Affective strategies have 6 items and measure to what extent students use them to regulate self-feeling, motivation and attitude toward learning.

Social strategies contain 6 items and assess how frequently students use them to learn through interaction with others.

\subsection{Data Collection and Analysis}

Data collected from questionnaires are analyzed by SPSS 17.0. 


\section{Results and Discussion of the Research}

\subsection{Descriptions of General Tendencies in Choice of Strategies}

Table 1. Mean strategy use in each of the six strategy groups

\begin{tabular}{llll}
\hline Strategy Group & Mean & Standard Deviation & Rank order of usage \\
\hline A memory & 2.74 & 0.47 & 5 \\
B cognitive & 2.84 & 0.49 & 3 \\
C compensation & 3.01 & 0.54 & 1 \\
D metacognitive & 2.91 & 0.59 & 2 \\
E affective & 2.80 & 0.55 & 4 \\
F social & 2.52 & 0.57 & 6 \\
\hline
\end{tabular}

Table 1 shows the mean strategy use in each of the categories for the entire strategy groups. The highest mean of the six strategies used by college students is compensation category (3.01), which is followed by metacognitive (2.91), cognitive (2.84), affective (2.80) and memory (2.74). And the least used strategy is social strategy (2.52) which refers to the strategies used in this category include communicative conversations, interactions using target language and reading English books etc.

The reason that compensation strategies are used the most often is related to the characteristics of compensation strategies which refer to the strategies that the language learner use to keep communication smooth because of inadequacy of language knowledge. In our study, social strategies are the ones whose frequency is the lowest. The fact is that face-to-face communication with native speakers of English in mainland is still largely confined, and social strategies which involve 'ask questions in L2' and 'ask native to correct me' and 'communicate with native speakers', are scarcely employed by students. This is closely related to China's traditional English teaching pattern, in which English teaching is typically teacher-oriented or examination-oriented.

\subsection{Correlation between Achievement Motivation and Use of Learning Strategies}

Table 2. Correlation between learning strategies and achievement motivation

\begin{tabular}{lllllllll}
\hline & Memory & Cognitive & Compensation & Metacognitive & Affective & Social & Mf & Ms \\
\hline Ms & .138 & $.211^{* *}$ & .78 & $.324^{*}$ & $.313^{*}$ & $.211^{* *}$ & $-.150^{*}$ & 1.000 \\
Mf & -.05 & -.07 & -.013 & -.015 & -.082 & -.44 & & \\
\hline
\end{tabular}

Note: $* *$. Correlation is significant at the 0.01 level (2-tailed).

*. Correlation is significant at the 0.05 level (2-tailed).

The results of correlation between achievement motivation and strategy use are presented in Table 4.2. Motive to achieve success (Ms) is positively correlated with four categories, i.e. cognitive (.211), metacognitive (.324), affective (.313), and social strategies (.211) and each correlation is significant at the .01 level; motive to avoid failure (Mf) is negatively correlated with all the strategies, and further it has no significant relationships with these strategies.

The goal of achievement-oriented activity is to succeed, to perform well in relation to a standard of excellence or in comparison with others who are competitors. Meanwhile, all appropriate language learning strategies are oriented toward the broad goal-communicative competence (Oxford, 1990); to a great extent, learning strategies contribute to one's language development. Metacognitive strategies help learners with pre-assessment and pre-planning, on-line planning and evaluation, and post-evaluation of language learning activities and of language use events. Cognitive strategies are highly useful for understanding, grouping and recalling new information. Affective strategies may contribute to reduction of anxiety and to self-encouragement. Social strategies aid learners in interacting with other learners and with native speakers. Therefore, for the sake of developing the communicative competence of their target language, learners with high Ms tend to apply a variety 
of learning strategies more frequently to accomplish their achievement goals.

Besides, the study indicates that learners considerably anticipate success, but shows little concern about failure. This is consistent with the characteristics of college students' psychology and personality, for they are still in their adolescence, during which their psychology development tends to become mature and strong senses of grow-up and independence emerge in their self-consciousness. Thus, their motive to achieve success appears strong in order to strive for recognition, independence and reliance.

Moreover, the findings show that people with high need for achievement employ all the six categories of strategies significantly more often than those whose achievement motivation are low. These findings support the statement made by Oxford and Nyikos (1989) that high motivation is linked with high-frequency use of language learning strategies.

Besides, some researchers have connected individual personality with achievement motivation. Atkinson (1966) has proposed that a stable personality of "risk-taking" is associated with achievement motivation. Learners with high motivation, other things being equal, will be those who construe the tasks that face them as medium-risk, and achievable. As a result, they are more likely to engage in the cumulative learning activities and try various strategies to achieve success. Within the Foreign Language Learning field, there has been an account of the role of risk-taking given by Skehan (1989). First of all, risk-taking in situations containing social interaction has been seen as likely to increase opportunities to hear language (and obtain input), and to speak language (and use output and engage in functional practice). Secondly, that risk-taking might be important in language learning lies in that the development of language involves restructuring one's existing language system. "And this can only proceed through hypotheses formation and hypothesis testing, then the successful learner is more likely to be one who takes his existing language system to the limit, and tries out risky hypotheses where feedback will be most revealing" (Skehan,1989). Therefore, good language learners with high need for achievement are more likely to extend their competence by taking a risk and employing various strategies in language learning, which is beyond their present proficiency.

4.2.1 The Effect of Different Levels of Achievement Motivation on Learning Strategies

Table 3. Step-wise regression analysis of achievement motivation and learning strategy

\begin{tabular}{llllll}
\hline Independent Variable & Dependent Variable & & & & \\
\hline Ms & cognitive & 0.045 & 8.896 & 0.211 & $2.983^{* *}$ \\
& Metacognitive & 0.1 & 22.392 & 0.324 & $4.732^{* * *}$ \\
& Affective & 0.093 & 20.8 & 0.313 & $4.561^{* * *}$ \\
& Social & 0.04 & 8.942 & 0.211 & $2.990^{* *}$ \\
\hline
\end{tabular}

Note: ${ }^{* *}$. Correlation is significant at the 0.01 level (2-tailed).

*.Correlation is significant at the 0.05 level (2-tailed).

In this analysis, a stepwise method was employed, aiming to investigate the effect of achievement motivation on strategy use. In Table 3, dependent variables are six categories of learning strategies, while independent variables are two aspects of achievement motivation, i.e. motive to achieve success (Ms) and motive to avoid failure (Mf).

According to step-wise regression method, coefficient (Beta) has two possible orientations: positive and negative. "Positive" means the strategies are used more often, while "negative" is just the opposite. " $R$ " " means the whole predictive power of the observed effects of achievement motivation on learning strategies or proficiency.

As presented in Table 3, motive to achieve success exerts direct regressive effects on four learning strategy categories, i.e. cognitive, metacognitive, affective and social strategies, and the path coefficients (Beta) are positive. However, motive to avoid failure has no direct effect on learning strategies. 


\subsection{Correlation between Goal-setting and Use of Learning Strategies}

Table 4. Correlation between goal-setting and learning strategies

\begin{tabular}{lllllll}
\hline & Memory & Cognitive & Compensation & Metacognitive & Affective & Social \\
\hline Self-Set Goal & 0.014 & $.162^{*}$ & $.274^{* *}$ & $.239^{* *}$ & 0.031 & -0.114 \\
Specific Goal & $.225^{* *}$ & $.304^{* *}$ & $.211^{* *}$ & $.420^{* *}$ & $.195^{* *}$ & $.171^{*}$ \\
Easily Attained Goal & 0.123 & 0.08 & $.185^{* *}$ & $.156^{*}$ & 0.124 & 0.042 \\
Attainable Goal & 0.011 & $.212^{* *}$ & $.164^{*}$ & $.171^{* *}$ & 0.124 & 0.041 \\
High Goal & 0.203 & $.319^{* *}$ & $.200^{* *}$ & $.180^{*}$ & 0.123 & $.218^{* *}$ \\
Short-Term Goal & 0.066 & 0.141 & $.272^{* *}$ & $.241^{* *}$ & 0.023 & 0.033 \\
Performance Goal & -0.088 & $-.210^{* *}$ & $.158^{*}$ & -0.057 & 0.051 & -0.106 \\
Mastery Goal & $.240^{* *}$ & $.248^{* *}$ & 0.17 & 0.087 & $.179^{*}$ & $.145^{*}$ \\
Strong Commitment To Goal & $.210^{* *}$ & $.283^{* *}$ & $.157^{*}$ & $.364^{*}$ & 0.092 & 0.093 \\
Weak Commitment To Goal & -0.112 & -0.065 & 0.063 & -0.53 & 0.067 & $-.229^{* *}$ \\
\hline
\end{tabular}

Note:**. Correlation is significant at the 0.01 level (2-tailed).

*.Correlation is significant at the 0.05 level (2-tailed).

The author applied correlation analysis method to detect the relationship between goal-setting and learning strategy use. According to the results in Table 4, ten of all the levels of goal-setting we chose has significant relations with learning strategy use. Cognitive, compensation and metacognitive strategies have significant relations with most levels of goal-setting, however, affective strategies has the least correlation with all the levels of goal-setting. The levels of 'specific goal', 'high goal' and mastery goal and 'strong commitment to goal' are significantly related to all or most of the six categories of learning strategies; Both 'performance goal' and 'weak commitment to goal' are negatively correlated to four categories of learning strategies, i.e. memory, cognitive, metacognitive and social strategies. Between 'mastery goal' and 'performance goal', the former is positively correlated with social strategies while the latter is negatively correlated with them.

This study also finds that the learners with a 'mastery goal' use learning strategies more often than those with a 'performance goal'. This finding is consistent with propositions by Dweck and Kegget (1988) and Lee, Locke and Latham (1989) that mastery goals are thought to lead to adaptive behavioral responses such as increased effort or strategy shifting, whereas performance goals give rise to maladaptive responses. For instance, 'mastery goal' is positively correlated with social strategies while 'performance goal' has negative relations with them. The learners with a goal of good mastery of English are inclined to pursue effective communication in English. But those with a 'performance goal' pay more attention to examinations; as a result, they tend to avoid spending time on communication.

4.4 Correlation between Goal-setting and Achievement Motivation

Table 5. Correlation between goal-setting and achievement motivation

\begin{tabular}{lccccc}
\hline & Self-Set Goal & Specific Goal & Short-Term Goal & Mastery Goal & Strong Commitment To Goal \\
\hline Ms & .011 & $.214^{* *}$ & $-.0149^{*}$ & $.163^{*}$ & $.150^{*}$ \\
Mf & $-.239^{* *}$ & -.128 & .177 & .014 & -.075 \\
\hline
\end{tabular}

Note: **. Correlation is significant at the 0.01 level (2-tailed).

*.Correlation is significant at the 0.05 level (2-tailed).

A correlation analysis was employed to probe whether there exists relationship between goal-setting and two aspects of achievement motivation, i.e. motive to achieve success and $m$ otive to avoid failure.

The results in Table 5 shows that motive to achieve success (Ms) has significant positive relations with three 
levels of goal-setting, i.e. 'specific goal', 'mastery goal', and 'strong commitment to goal', but is negatively related with the level of 'short-term goal'. On the other hand, motive to avoid failure (Mf) is negatively related with 'specific goal' and 'strong commitment to goal' and negatively related to 'self-set goal' significantly, however, it is positively related to 'short-term goal' and 'mastery goal'.

Just like Qin Xiaoqing (2002) proposes in her causal model of motivation that goal-setting is a very important cognitive mediator between Motivational Antecedents and Motivational Behavior. The finding in this study indicates that learners with high motive to achieve success tend to set specific goal and mastery goal and have strong goal commitment. Furthermore, learners with high motive to achieve success are more unlikely to set short-term goals.

This finding is also consistent with Qin Xiaoqing (2002)'s result that learners who aimed at passing all required examinations preferred to set a mastery goal, but seems somewhat different from that by Ames and Archer (1988) that learners focusing on examination-related purpose have a preference for performance goal. This finding is reasonable in the context of college English learners in China. One explanation for it is that unlike learners in middle school who face fierce competition in MET, college learners do not place much emphasis on social comparison and they are more concerned with mastery of the English language. An alternative reasonable explanation is that all kinds of examinations in universities are more and more mastery of language biased. Therefore, learners only with short-term goal need to improve their English competence and performance for the sake of long-term goal.

\section{Conclusion}

\subsection{Major Findings}

The findings of this study are summarized as follows:

In terms of the use of different learning strategies among students in study, compensation and metacognitive strategies are reported as being used the most frequently, while social strategies are least used.

Concerning the relationship between achievement motivation and learning strategies, the study shows that motive to achieve success (Ms) is positively and significantly correlated with four of the six types of learning strategies, i.e. cognitive, metacognitive, affective and social strategies. On the contrary, motive to avoid failure (Mf) is negatively but not significantly correlated with all the strategies.

With regard to goal setting and strategy use, the study shows that all six categories of learning strategies are significantly correlated with 'specific goal', and 'high goal' setting is significantly related with all the six categories of learning strategies except affective strategies. This study also finds that the learners with a 'mastery goal' use learning strategies more often than those with a 'performance goal'.

As for the relationship of goal-setting and achievement motivation, learners who set specific goal and mastery goal and have strong goal commitment tend to have high motive to achieve success. Furthermore, learners with high motive to achieve success are more unlikely to set short-term goals.

\subsection{Implications}

The result of this study shows that learning strategies play an indispensable part in foreign language learning. Besides, significant influence of achievement motivation and goal-setting on learning strategies can be also seen from this study. Thus, teachers should know well the relationship between achievement motivation, goal-setting and learning strategies. Teachers should help students be aware of the wide range of strategy options available to them; meanwhile, it is important to realize the individual differences in strategy use. Considering these, this study suggests a number of implications and extensions for the classroom.

First of all, teachers' methodology should adapt to its changes to satisfy students' various needs. As Oxford (1990) points out, "New teaching capacities also include identifying students' learning strategies, conduction training on learning strategies, and helping learner become more independent". Some practical principles are provided for promoting strategy use to develop learner autonomy.

Secondly, in order to promote more efficient learning and better outcome, teachers should help learners enhance achievement motivation and use effective learning strategies.

Last but not least, due to the importance of goal-setting to students' motivation, achievement and use of learning strategies, teachers should help students to set specific and appropriate goals based on their respective self-efficacy, tailored to their specific needs. And what is more important for teachers is to help students to build their own intrinsic reward by emphasizing mastery of specific goals. Learning classroom must focus on using clear goals and standards for students to master a language, which leads to enhance students' achievement 
motivation.

\section{Reference}

Abraham, R. G., \& Vann, R. J. (1987). Strategies of two language learners: a case study. In A. Wenden, \& J. Rubin (Eds.). Learner strategies in language learning (pp. 85-102).

Ames, C. (1981). Competitive Versus Individualistic Goal Structures: The Salience of Past Performance Information for Causal Attributions and Affect. Journal of Educational Psychology, 73(3), 411-418. https://doi.org/10.1037/0022-0663.73.3.411

Ames, C., \& Archer, J. (1998). Achievement goals in the classroom: Student learning strategies and motivation process. Journal of Educational Psychology, 80, 267-269.

Atkinson, J. W wt al. (1996). A theory of achievement motivation. New York: Wiley.

Bernaus, M., \& Gardner, R. C. (2008). Teacher Motivation Strategies, Students Perceptions, Student Motivation and English Achievement.

Cohen, A. D. (2014). Strategies in Learning and Using a Second Language.

Damon, W., \& Lerner, R. M. (2008). Child and Adolescent Development: An Advanced Course.

Dornyei, Z. (1990). Motivation and motivating in the foreign language classroom. The Modern Language Journal.

Dornyei, Z., \& Otto, I. (2001). Motivation in action: A process model of L2 motivation.

Dweck, C. S., \& Leggett, E. L. (1988). A social-cognitive approach to motivation and personality. Psychological Review, 95(2), 256-273. https://doi.org/10.1037/0033-295X.95.2.256

Ehrman, M. E., \& Oxford, R. L. (1990). Adult language learning styles and strategies in an intensive training setting. The Modern Language Journal. https://doi.org/10.1111/j.1540-4781.1990.tb01069.x

Ellis, R. (1994). The study of second language acquisition. Oxford: Oxford University Press.

Gardner, R., \& Lambert, W. E. (1959). Motivational variables in second language acquisition. Canadian Journal of Psychology, 13, 266-272. https://doi.org/10.1037/h0083787

Gardner, R. C., \& MacIntyre, P. D. (1992). A student's contributions to second-language learning. Part I: cognitive variables. Lang. Teach, 25, 211-220. https://doi.org/10.1017/S026144480000700X

Gardner, R. C., \& MacIntyre, P. D. (1993). A student's contributions to second-language leaning. Part II: affective variables. Lang. Teach, 26, 1-11. https://doi.org/10.1017/S0261444800000045

Gardner, R. C. et al. (1997). Towards a full model of second language learning: an empirical investigation. The Modern Language Journal, 81, 344-362. https://doi.org/10.1111/j.1540-4781.1997.tb05495.x

John, B. M. (2005). Organizational Behavior 1: Essential Theories of Motivation and Leadership.

Lee, S. H., Palmer, S. B., \& Wehleyer, M. L. (2009). Goal Setting and Self-Monitoring for Students With Disabilities.

Locke, A., \& Latham, G. (1989). A Theory of Goal Setting and Task Performance.

Locke, A., \& Latham, G. (2006). New Directions in Goal-Setting Theory.

Moeller, A. J., Theiler, J. M., \& Wu, C. R. (2012). Goal Setting and Student Achievement: A Longitudinal Study. The Modern Language Journal. https://doi.org/10.1111/j.1540-4781.2011.01231.x

Okada, M., Oxford, R. L., \& Abo, S. (1996). Not all alike: Motivation and learning strategies among students of Japanese and Spanish in an exploratory study. In Language learning motivation: Pathways to the new century (pp. 105-120). Honolulu, HI: University of Hawaii at Manoa.

Oxford, R. L., \& Crookall, D. (1989). Research on language learning strategies: methods, findings, and instructional issues. The Modern Language Journal, 73, 404-419. https://doi.org/10.1111/j.1540-4781.1989.tb05321.x

Oxford, R. L., \& Burry-Stock, J. A. (1995). Assessing the use of language learning strategies worldwide with the $\mathrm{ESL} / \mathrm{EFL}$ version of the strategy inventory for language learning (SILL). System, 23, 1-23. https://doi.org/10.1016/0346-251X(94)00047-A

Oxford, R. L., \& Nyikos, M. (1989). Variables affecting choice of language learning strategies by university students. The Modern Language journal, 73, 291-300. https://doi.org/10.1111/j.1540-4781.1989.tb06367.x 
Oxford, R. L. (1989). Use of language learning strategies: a synthesis of studies with implications for strategy training. System, 17, 235-247. https://doi.org/10.1016/0346-251X(89)90036-5

Oxford, R. L. (1990). Language learning strategies: What every teacher should know. Boston: Heinle \& Heinle.

Politzer, R. L. (1983). An exploratory study of self-reported language learning behaviors and their relation to

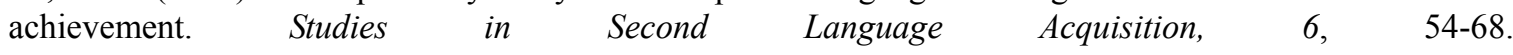
https://oi.org/10.1017/S0272263100000292

Singh, K. (2011). Study of Achievement Motivation in Relation to Academic Achievement of students. International Journal of Educational Planning \& Administration, 1, 161-171.

Skehan, P. (1989). Individual differences in second-language learning. London: Edward Arnold.

Tella, A. (2007). The Impact of Motivation on Student's Academic Achievement and Learning Outcomes in Mathematics among Secondary School Students in Nigeria. Eurasia Journal of Mathematics, Science \& Technology Education, 2, 149-156. https://doi.org/10.12973/ejmste/75390

Williams, M., \& Burden, R. (2000). Psychology for Language Teachers. Cambridge University Press.

Wen, Q. F. (2001). Developmental patterns in motivation, beliefs and strategies of English learners in China. Foreign language teaching and Research, 33, 105-110.

\section{Copyrights}

Copyright for this article is retained by the author(s), with first publication rights granted to the journal.

This is an open-access article distributed under the terms and conditions of the Creative Commons Attribution license (http://creativecommons.org/licenses/by/4.0/). 